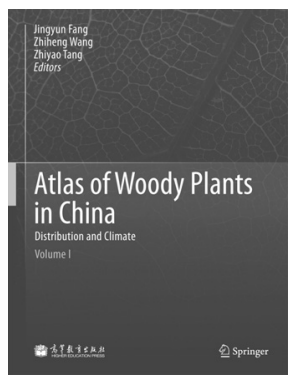

\title{
Jingyun Fang, Zhiheng Wang, Zhiyao Tang (editors). Atlas of Woody Plants in China: Distribution and Climate
}

\author{
Beijing: 2 Vol., Higher Education Press/Heidelberg; New York: \\ Springer, 2011. Disponible también como e-book. 1970 p.
}

\author{
Andrés Moreira-Muñoz ${ }^{1}$
}

Atendiéndose fielmente a la tradición de los atlas como colección de mapas, nos enfrentamos a esta monumental obra publicada en dos grandes volúmenes que casi suman 2.000 páginas. Se trata de una colección sistemática de más de 11.000 mapas que representan la distribución geográfica de las plantas leñosas de China. Realizar un atlas de plantas de este vasto y diverso país no es tarea menor: se trata de uno de los países considerados a escala global como megadiversos. La diversidad de China supera las 30.000 especies de plantas, es decir, alberga más especies botánicas que Europa y América del Norte juntas. En la obra se presenta aproximadamente un tercio de esta diversidad, que corresponde a las plantas leñosas; esto es, árboles (sobre $4 \mathrm{~m}$ de alto), arbustos (menores de $4 \mathrm{~m}$ ) y lianas.

El proyecto de compilación de mapas comenzó el año 2003. La base de datos fue construida en 4 pasos: primero se generó la lista de las plantas leñosas nativas, a partir de los trabajos taxonómicos más recientes como la Flora de China (Flora Reipublicae Popularis Sinicae), siendo excluidas las especies de cultivo. La base consta de 11.045 plantas leñosas, incluyendo 1.355 variedades y subespecies pertenecientes a 1.175 géneros y 170 familias. En seguida se hizo la revisión de la distribución geográfica de cada taxón, sobre la base de floras provinciales y locales, monografías y estudios, así como ejemplares de

1 Instituto de Geografía, Pontificia Universidad Católica de Chile (Chile).E-mail: asmoreir@uc.cl herbario. En tercer lugar se invitó a 21 botánicos y ecólogos de todo el país para revisar y mejorar tanto los aspectos de distribución como aspectos taxonómicos y de nomenclatura. Por último, por medio de la aplicación MapObjects de ESRI, se generó la interfaz de manejo de la base de datos, sobre la base de los 2.408 distritos en que se divide administrativamente el país.

Las páginas del Atlas presentan 6 especies (mapas) por página, ordenadas según el sistema filogenético de la Flora de China. A cada mapa se agrega el nombre científico, el nombre en chino, y la forma de vida (árbol, arbusto, liana) así como diferentes variables climáticas asociadas a la especie. Dichas variables climáticas han sido obtenidas de la base de datos global Worldclim, de aproximadamente $1 \mathrm{~km}$ de resolución.

La visión de síntesis de la riqueza de plantas leñosas chinas muestra un patrón latitudinal en su porción oriental, siendo mayor el número de especies en montañas del sur bajo un clima tropical (más de 1.000 especies en algunos distritos), como los Montes Hengduan, Yunnan del Sur, o las montañas de Nanling. Comparativamente la porción occidental del país es más pobre en especies leñosas, sobre todo el Plateau Tibetano, el Desierto de Taklimakan y la Cuenca de Sichuan. En todo caso no debe olvidarse que se trata "solamente" de las especies leñosas; es muy probable que de continuarse en el futuro el tratamiento con los otros dos tercios de la flora de China, regiones de praderas o matorrales sorprendan 
con altos valores de riqueza (ver Jia et al., 2011).

El Atlas tiene un enorme valor referencial $y$, tal como ha sido propuesto en numerosas ocasiones (e.g. Morrone y Espinosa, 1998), puede llegar a tener una fuerte implicancia en temas de biogeografía, como por ejemplo la conservación de la biodiversidad. El conocimiento adecuado de la distribución geográfica de las especies es fundamental para superar lo que se ha denominado el "vacío" de Wallace, esto es, la dificultad de tomar decisiones con información limitada de la distribución de los taxones de cualquier grupo biótico (Richardson \& Whittaker, 2010). A pesar de los avances que se ven actualmente en la generación de modelos de distribución, dichos modelos serán más robustos, por ejemplo, en predicciones asociadas al cambio climático, en la medida en que los datos de distribución sean fiables tanto geográfica como taxonómicamente, y posean una densidad relativamente adecuada al espacio en el cual se realicen los análisis (Pliscoff y Fuentes-Castillo, 2011) En este sentido, el Atlas de las Plantas Leñosas de China constituye un gran avance no solo para la ciencia botánica china, sino un gran ejemplo a seguir por otros países megadiversos, y aquellos no tan diversos pero con características florísticas tan peculiares como el caso de Chile.

\section{Referencias bibliográficas}

JIA, X.X.; SHAO, M.G. \& WEI, X.R. Richness and composition of herbaceous species in restored shrubland and grassland ecosystems in the northern Loess Plateau of China. Biodiversity and Conservation, 2011, Vol. 20, $\mathrm{N}^{\circ} 14$, p. 3435-3452.

Morrone, J.J. y Espinosa, D. La relevancia de los atlas biogeográficos para la conservación de la biodiversidad mexicana. Ciencia, 1998, Vol. 49, № 3, p. 12-16.

Pliscoff, P. y Fuentes-Castillo, T. Modelación de la distribución de especies y ecosistemas en el tiempo y en el espacio: una revisión de las nuevas herramientas y enfoques disponibles. Revista de Geografía Norte Grande, 2011, Vol. 48, p. 61-79.

Richardson, D.M. \& Whittaker, R.J. Conservation biogeography - foundations, concepts and challenges. Diversity and Distributions, 2010, Vol. 16, № 3, p. 313-320. 